\title{
PROBLEM-BASED LEARNING AS A PEDAGOGICAL APPROACH FOR PREPARING STATISTICS GRADUATES
}

\author{
Gerald Iacullo \\ Berkeley College, New York USA \\ gji@berkeleycollege.edu
}

The purpose of this study was to explore selected reform-oriented practices centered on Problembased Learning (PBL). The target group was developmental math instructors who provide formative level instruction that can be defining in developing quantitative reasoning. Data were collected using a 10-item scale developed from a set of criteria that focused on knowledge acquisition, critical thinking, active learning, multiple representations, skills development, and assessment. The majority of the PBL strategies were highly rated as either "usually" or "always" (ranging from $72 \%$ to $90 \%$ ), however, some key strategies were lacking, particularly critical thinking, active learning, and multiple representations, which were rated as either "rarely" or "sometimes" (ranging from 39\% to 63\%). The results of this study provide insight into the use of PBL strategies designed to promote quantitative literacy among college students, and identifying instructor strengths and weaknesses that can be addressed in professional development programs.

\section{BACKGROUND}

Quantitative Reasoning (QR) is the ability to identify and apply mathematical and statistical knowledge to solve real-world problems (Steen, 2001). QR has been identified as an important $21^{\text {st }}$ Century workforce competency and, hence, an essential skill for today's college graduates. In this regard, many colleges have been taking steps to ensure that their graduates are ready to successfully enter an increasingly quantitative global community (Madison \& Deville, 2014). Yet, recent evidence has found that many college students lack the competencies necessary for quantitative reasoning. In a recent study on student learning achievement (AAC\&U, 2017), limitations were noted in college students' ability to make and evaluate important assumptions in data analysis and in their ability to draw appropriate conclusions based on the quantitative analysis of data. Moreover, a majority (55\%) of college seniors reported that they never or sometimes used numerical information to examine real-world problems, or evaluated other people's conclusions from numerical information (NSSE, 2015). These trends suggest a need for colleges to assess their curricula and pedagogy at all levels and make the changes necessary to ensure that their graduates are adequately prepared.

Mathematics and statistics courses seem like a natural setting for improving students' quantitative reasoning skills. However, mathematics courses have tended to focus on the acquisition of mathematical concepts, algorithms, formulas, and procedures, and less on students' ability to apply them to a wide variety of authentic contexts, which is an essential characteristic of quantitative reasoning (Hughes-Hallett, 2003). Consider developmental mathematics courses that are meant to provide underprepared students with the transferable skills and knowledge necessary to effectively engage in college-level courses. These courses have tended to concentrate on computational and procedural fluency in a traditional lecture, practice and drill format, with little regard to context, conceptual understanding, and problem solving (Grubb, 2010; Stigler, Givvin, \& Thompson, 2010). As such, the research would suggest that developmental mathematics courses are not adequately providing students with the competencies (communication, reasoning, problem solving, and representation) needed to foster quantitative reasoning (An, 2015; Niss, 2003; Turner, 2011).

While there is no universally accepted instructional model for promoting QR, research evidence has increasingly demonstrated that problem-based learning (PBL) is very effective in fostering quantitative reasoning. Unlike traditional teaching approaches in which content and procedural skills are mastered before problem solving is attempted, students, in a PBL environment, acquire the requisite knowledge and skills as they engage in a process of solving authentic problems (Cheaney \& Ingebritsen, 2005). As the research literature (Hmelo-Silver, 2004, Savery, 2006; Turnstall \& Bosse, 2015) indicates, PBL is characterized by

- the use of ill-structured or open-ended authentic problems that fit with the students' prior 
knowledge;

- self-directed and small group problem solving;

- instructors who model higher-order thinking and scaffold student learning through selected curricula material.

Furthermore, the active learning strategies (based on a constructivist approach to learning) that promote the goals of PBL (conceptual understanding, and transferable knowledge and skills) align with key competencies needed for quantitative reasoning (An, 2015; Niss, 2003; Turner, 2011), in particular

- $\quad$ problem solving - applying and modifying appropriate strategies to solve problems

- representing - selecting the appropriate representation and switching between various representations

- communicating - explaining one's ideas and working collaboratively with others

- reasoning - devising and assessing mathematical and statistical arguments.

\section{THEORETICAL FRAMEWORK}

This study is rooted in a constructivist approach to learning. Consequently, there is a fundamental assumption that knowledge, meaning, and understanding are constructed by the learner (Hassad, 2011). Moreover, the problem or task, which is authentic and has some relevance to the learner, provides the motivation whereby solving the problem affords the student the chance to master and add to what they already know, thus encouraging further learning (Wilder, 2015). Furthermore, learning takes place in context and through social discourse. In other words, the mathematics or statistics learning environment provides the context in which students and teachers engage in the discovery of meaning and understanding, and the learners construct, with the assistance of others, an individual meaning or solution to a complex problem.

Essentially, the constructivist approach suggests a set of reform-oriented instructional strategies that foster conceptual understanding and students' problem solving skills. Included are knowledge acquisition, collaborative and cooperative learning, use of multiple representations, communicating mathematically, critical thinking, skills development, and metacognitive strategies, including formative assessment, self-reflection, and feedback (Cai \& Lester, 2010; Cheaney \& Ingebritsen, 2005, Wilder, 2015). Yet, empirical evidence regarding the adoption and level of use of these strategies is lacking.

\section{OBJECTIVE}

The purpose of this study was to explore selected reform-oriented practices centered on problem-based learning among mathematics instructors who teach foundation courses toward supporting quantitative reasoning. Selected instructor characteristics were also examined in order to determine if there were differences in the frequency of use of these practices.

\section{METHODOLOGY}

The participants in this study were full-time and part-time instructors at two- and four-year regionally accredited postsecondary institutions in the United States who taught developmental mathematics courses and had full responsibility for these courses. A purposive (or maximum variation) sampling design was used in order to allow for the selection of participants who represented the full diversity of problem-based learning instructional practices.

This exploratory study employed a cross-sectional design, which facilitated the collection of relevant data at a single point in time. Specifically, data were collected by means of a single Web-based questionnaire, consisting of a PBL scale and selected instructor characteristics. The PBL scale consisted of 10 items which were identified as essential for fostering students' conceptual understanding and problem-solving ability (Cai \& Lester, 2010). Specifically, the items focused on knowledge acquisition, and key reformed-oriented instructional strategies such as, critical thinking, active learning, multiple representations, skills development, and assessment.

Descriptive statistics (frequencies and percentages) were used to report the responses to each item on the PBL scale and on the instructor characteristics. In addition, chi-square test of independence as well as Pearson's correlation and its nonparametric equivalent, Spearman's correlation, were used to determine if there were significant associations between the use of each of 
the items on the scale and selected instructor characteristics (age, gender, number of years teaching developmental math, highest academic degree, faculty employment status, and academic concentration or specialization). All data were analyzed using SPSS (version 24).

\section{RESULTS}

The sample consisted of 160 instructors who taught developmental mathematics at regionally accredited two- or four-year colleges located in 32 different states. These instructors reported a considerable amount of time teaching developmental mathematics, with an average of 16 years $(\mathrm{SD}=10$ years) and median of 15 years. The median age of these instructors was 45 years, and the majority ( 87 or $53 \%$ ) were women. One hundred and twenty-eight $(80 \%)$ were full-time instructors. One hundred and eight instructors (68\%) possessed a Master's degree, and $43(27 \%)$ indicated they had a doctoral degree. The majority of the instructors $85(53 \%)$ claimed a specialization in mathematics, with $44(27 \%)$ possessing a degree in mathematics education. The academic concentration of the remaining 28 instructors (18\%) was distributed as follows: developmental education $12(8 \%)$, education $4(2 \%)$, statistics $6(4 \%)$, and other $6(4 \%)$.

Table 1: Instructors' Use of PBL Strategies

\begin{tabular}{lccccc}
\multicolumn{1}{c}{ ITEMS } & Never & Rarely & Sometimes & Usually & Always \\
\hline $\begin{array}{l}\text { (1) The problem has important, useful } \\
\text { mathematics embedded in it. }\end{array}$ & - & $1(1 \%)$ & $19(12 \%)$ & $74(46 \%)$ & $66(41 \%)$ \\
$\begin{array}{l}\text { (2) The problem requires higher-level } \\
\text { thinking and problem solving. }\end{array}$ & - & $2(1 \%)$ & $64(40 \%)$ & $71(44 \%)$ & $23(14 \%)$ \\
$\begin{array}{l}\text { (3) The problem contributes to the } \\
\text { conceptual development of students. }\end{array}$ & - & - & $45(28 \%)$ & $76(48 \%)$ & $39(24 \%)$ \\
$\begin{array}{l}\text { (4) The problem creates an } \\
\text { opportunity for the teacher to assess } \\
\text { what his or her students are learning }\end{array}$ & - & $3(2 \%)$ & $29(18 \%)$ & $79(49 \%)$ & $49(30 \%)$ \\
and where they are experiencing \\
difficulty.
\end{tabular}

The majority of the PBL strategies were highly rated as either usually or always (ranging from $72 \%$ to $90 \%$ ). Those strategies that focused on content and skills development elicited the highest number of usually or always responses (see Table 1). That is, approximately $88 \%$ of instructors reported that they consistently (usually or always) use problems or tasks that have useful or important mathematics embedded in it (Item 1), and $87 \%$ use problems that promote the skillful use of mathematics (Item 9). The overwhelming majority (90\%) of instructors consistently (usually or always) provide opportunities for the students to practice important skills (Item 10).

In contrast, some key strategies were lacking, as evidenced by approximately $42 \%$ of the instructors reporting rarely or sometimes (see Table 1) to each of the following: 
- using problems that require higher-level thinking or problem-solving (Item 2)

- using problems that encourage student engagement and discourse (Item 7).

Regarding multiple representations, approximately $63 \%$ of instructors never, rarely, or sometimes engage students in tasks that allow for various solutions or different positions to be taken and defended (Item 6), and approximately $39 \%$ of them rarely or sometimes use problems that involve the use of multiple ways to solve the problem (Item 5).

There were no statistically significant associations observed in the use of the PBL instructional strategies based on selected instructor characteristics (gender, age, highest earned degree, faculty employment status, number of years teaching developmental mathematics, and academic concentration or specialization).

\section{DISCUSSION AND IMPLICATIONS}

The purpose of this study was to explore selected reform-oriented practices centered on problem-based learning among mathematics instructors who teach foundation courses toward supporting quantitative reasoning. This study identified a relatively high level of use of the PBL strategies, which is similar to Bonham and Boylan (2011) who reported an increase in use of best instructional practices in developmental mathematics programs. In particular, the most consistently used strategies by the instructors in this study were those that promote skills development and knowledge acquisition. However, the findings in the current study are not supported by Hodara (2011), and Stigler et al. (2010) who found little evidence in the use of reform-oriented instructional practices (based on constructivist learning approaches) by instructors who teach developmental mathematics.

Findings from this study also indicate that improvement is needed in the use of key active learning strategies. In particular, it was surprising to observe the extent to which instructors do not consistently use problems that allow for different decisions or positions to be taken and defended (Item 6). The value of open-ended, authentic problems is that they not only stimulate student learning, but they also provide students the opportunity to develop critical learning and reasoning strategies (Hmelo-Silver, 2004). Specifically, in order for students to justify or explain an argument and to organize their work on authentic problems or tasks, it is important that they have an understanding of the relationship between different representational forms and are able to select and utilize appropriate representations as they work toward a solution. (Edy, 2015; Pape \& Tchoshanov, 2001). Moreover, given the role that multiple representations play in improving students' quantitative skills (Hodara, 2011) and in strengthening the relationship between procedural fluency and conceptual understanding (Edy, 2015), it is important that instructors of foundation or developmental courses begin to explicitly focus on the relationships between and among different representations as earlier as possible.

To a lesser degree, there is a concern regarding the use of strategies that foster critical thinking, communication, and collaboration. That is, there seemed to be a reluctance among a considerable proportion of the instructors to consistently use problems that foster higher-order thinking and problem solving (Item 2), and student engagement and discourse (Item 7). Although Raiyn and Tilchen (2015) identified higher-order thinking skills, including organizing, comparing, contrasting, evaluating, and developing innovative strategies, as essential for problem-solving, they also acknowledged that developing students' high-order thinking skills can be very challenging (which may account for the results in this study). In the same way, there is ample evidence, as noted by Tadesse \& Gilles (2015), to support the role that collaborative learning activities, including small group problem solving, have on helping students, especially low achievers, to communicate their ideas and better understand their thought processes. Yet, the findings in this study may mirror the observations of Tadesse and Gilles (2015) that creating well-structured and challenging collaborative learning experiences takes commitment and practices on the part of instructors.

It is not possible to ascertain from the data gathered for this study the exact reasons why instructors preferred some strategies to others. One possible explanation may be, as Hassad (2011) noted, that selected instructor beliefs and attitudes regarding the teaching and learning experience might be salient factors in an instructor's decision-making process to adopt innovative instructional practices. Such beliefs can be wide-ranging, encompassing the convictions, thoughts, and values 
that teachers may hold regarding all aspects of teaching and learning. With respect to this study, it might include instructors' perceptions of the usefulness of PBL strategies and the belief in their ability to implement these strategies. Accordingly, professional developmental activities aimed at facilitating the use of such strategies need to address the relationship between instructors' beliefs and their instructional practices as well as the impact it has on student learning.

There is another possible reason for the use of some strategies over others. Instructors when faced with certain situations prioritize their goals and use instructional practices that are more expedient even if they seem to conflict with their beliefs (Leatham, 2007). In particular, the level of unpreparedness of students enrolled in developmental mathematics courses is well documented (Jeong, \& Cho, 2010) and presents a challenge to those teaching them. As such, instructors may appreciate that the use of multiple representations or teamwork promotes QR and is needed for today's workplace but also recognize that students at certain developmental levels have difficulty when these strategies are applied. In these instances, programs could be implemented that involve both a discussion on the effectiveness of scaffolding to foster the development of students' problem-solving skills as well as a demonstration on how to adapt certain strategies, like multiple representations, to the student's ability and prior knowledge.

This study should be viewed as exploratory and preliminary, and the findings should be viewed in that light. The lack of variability based on instructor characteristics could be attributed to response bias associated with Likert-type scales. Of course, it could be conceivable that the instructors in this study actually believe they are using these strategies with a lack of understanding of what they are. Further research is needed to determine if the findings in this study are indicative of others who teach foundation or developmental mathematics courses (or college-level mathematics and statistics course) toward supporting quantitative reasoning.

\section{ACKNOWLEDGEMENTS}

Special thanks to the administration of Berkeley College for supporting my participation in the IASE 2017 Satellite Conference and to Dr. Rossi Hassad for his support and invaluable advice throughout this project.

\section{REFERENCES}

An, N. T. T. (2013). Using mathematization to develop student's quantitative literacy competencies. Southeast-Asian Journal of Sciences, 2(2), 213-220

Association of American Colleges and Universities (AAC\&U). (2017). On Solid Ground. Washington, DC: Association of American Colleges and Universities

Bailey, T., Jeong, D. W., \& Cho, S. W. (2010). Referral, enrollment, and completion in developmental education sequences in community colleges. Economics of Education Review, 29, 255-270.

Bonham, B. S., \& Boylan, H. R. (2011). Developmental mathematics: Challenges, promising practices, and recent initiatives. Journal of Developmental Education, 34(3), 2-4.

Cai, J., \& Lester, J. (2010). Why is teaching with problem solving important to student learning? Reston, VA: National Council of Teachers of Mathematics

Cheaney, J., \& Ingebritsen, T. (2005). Problem-based learning in an online course: A case study. International Review of Research in Open and Distance Learning, 6(3), 1-18

Edy, T. (2015). Effectivity of Problem Based Learning (PBL) in improving students' mathematical representation. Proceeding of International Conference on Research, Implementation and Education of Mathematics and Sciences 2015. Yogyakarta, Indonesia: Yogyakarta State University.

Grubb, W. N. (2010). The quandaries of basic skills in community colleges: View from the classroom. New York: Columbia University, Teachers College, National Center for Postsecondary Research.

Hassad, R. A. (2011). Constructivist and behaviorist approaches: Development and initial evaluation of teaching practice scale for introductory statistics at the college level. Numeracy, 4(2): Article 7. DOI: http://dx.doi.org/10.5038/1936-4660.4.2.7

Hmelo-Silver, C. E. (2004). Problem-based learning: What and how do students learn? Educational Psychology Review, 16(3), 235-266. 
Hodara, M. (2011). Reforming mathematics classroom pedagogy: Evidence-based findings and recommendations for the developmental math classroom (CCRC Working Paper No. 27, Assessment of Evidence Series). New York: Columbia University, Teachers College, Community College Research Center.

Hughes-Hallett, D. (2003). The role of mathematics courses in the development of quantitative literacy. In B. L. Madison \& L. A. Steen (Eds.), Quantitative Literacy: Why Numeracy Matters for Schools and Colleges (p. 91-98). Princeton: National Council on Education and the Disciplines.

Leatham, K. R. (2006). Viewing mathematics teachers' beliefs as sensible systems. Journal of Mathematics Teacher Education, 9(1), 91-102.

Madison, B. L., \& Deville, D. (2014). Beyond calculation. Peer Review 16(3), 9-12.

National Survey of Student Engagement (NSSE). (2015). Engagement Insights: Survey Finding on the Quality of Undergraduate Education-Annual Results 2015. Bloomington, IN: Indiana University Center for Postsecondary Research.

Niss, M. A. (2003). Quantitative literacy and mathematical competencies. In B. L. Madison, \& L. A. Steen (Eds.), Quantitative literacy: why numeracy matters for schools and colleges (pp. 215-220). Princeton: National Council on Education and the Disciplines.

Pape, S., \& Tchoshanov, M. (2001). The role of representation(s) in developing mathematical understanding. Theory into Practice, 40(2), 118-127.

Raiyn, J., \& Tilchin, O. (2015). Higher-order thinking development through adaptive problembased learning. Journal of Education and Training Studies, 3(4), 93-100.

Savery, J. R. (2006). Overview of problem-based learning: Definitions and distinctions. The Interdisciplinary Journal of Problem-based Learning, 1(1), 9-20.

Steen, L. A. (2001). Mathematics and democracy: The case for quantitative literacy. Princeton, NJ: National Council on Education and the Disciplines. Retrieved from http://www.maa.org/sites/default/files/pdf/QL/MathAndDemocracy.pdf

Stigler, J., Givvin, K., \& Thompson, B. (2010). What community college developmental mathematics students understand about mathematics. MathAMATYC Educator, 1(3), 4-16.

Tadesse, T., \& Gillies, R. (2015). Nurturing cooperative learning pedagogies in higher education classrooms: Evidence of instructional reform and potential challenges. Current Issues in Education, 18(2).

Tunstall, S. L., \& Bossé, M. J. (2015). Promoting numeracy in an online college algebra course through projects and discussions. Numeracy 8(2), Article 10. Retrieved from DOI: http://dx.doi.org/10.5038/1936-4660.8.2.10

Turner, R. (2011). Identifying cognitive processes important to mathematics learning but often overlooked. Australian Mathematics Teacher, 67(2), 22-26.

Wilder, S. (2015). Impact of problem-based learning on academic achievement in high school: A systematic review. Educational Review, 67(4), 414-435. 